\title{
Student Perspective on Assessment for Learning
}

Christopher DeLuca ${ }^{a}$, Allison Chapman ${ }^{\text {a }}$, Danielle LaPointe-McEwan ${ }^{\mathrm{a}}$, \& Don A. Klinger ${ }^{a}$

aFaculty of Education, Queen's University, Kingston, Canada

Full Citation:

Christopher DeLuca, Allison E. A. Chapman-Chin, Danielle LaPointe-McEwan \& Don A. Klinger (2018) Student perspectives on assessment for learning, The Curriculum Journal, 29:1, 77-94, DOI: 10.1080/09585176.2017.1401550

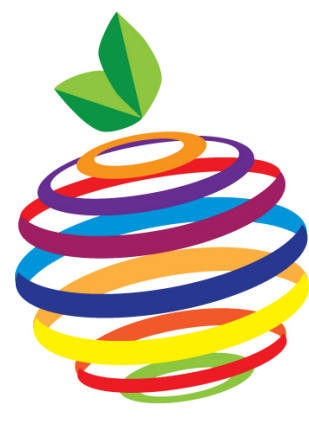

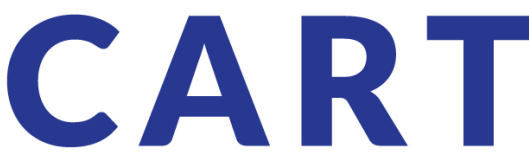

Classroom Assessment Research Team cdeluca.com
Contact:

Christopher DeLuca cdeluca@queensu.ca @ChrisDeLuca20 


\begin{abstract}
Assessment for learning (AfL) has become a widespread approach across many educational systems. To date, AfL research has emphasized teachers' knowledge, skills, and practices, with few studies examining students' responses to an AfL pedagogical approach. The purpose of this research was to focus directly on students' perspectives on their use and value of AfL approaches through a survey of $1079 \mathrm{~K}-12$ students and portfolio-based interviews with 12 purposefully selected students. Survey data were analyzed through descriptive and inferential statistics across grade levels. Interview data were analyzed using standard thematic coding processes. Students most frequently used and valued teacher feedback and success criteria to support their learning. Peer feedback was the least valued AfL approach for all students. Some significant differences between grade levels were noted. Our results suggest that using AfL approaches is a learned behaviour; students need to be explicitly taught about AfL concepts, terminology, and use over time. This study also highlights that AfL implementation requires sustained focus, research, and support in schools and classrooms for students to value and fully benefit from assessment-based teaching.
\end{abstract}

Keywords: assessment for learning, formative assessment, student learning, classroom assessment 
Assessment for learning (AfL) has become a dominant discourse across educational policies throughout the world and provides a compelling alternative to traditional large-scale testing mandates by squarely focussing on student learning as the primary purpose of assessment (e.g., Birenbaum et al., 2015; Ireland Department of Education and Skills, 2012; Hayward \& Spencer, 2010; New Zealand Ministry of Education, 2011; Ontario Ministry of Education, 2010). Since Black and Wiliam's (1998) research synthesis on formative assessment, researchers and policymakers alike have taken-up this feedback-driven pedagogical approach, which promises to improve teaching practices and enhance student outcomes. To this end, contemporary research has primarily served to re-conceptualize formative assessment as AfL and provide guidelines, principles, and approaches to support teachers' integration of assessment throughout their teaching practice. Dialogues across literature have focus on defining AfL, documenting its evidentiary basis, and describing implementation approaches across contexts (Bennett, 2011; Swaffield, 2011). To date, the emphasis in empirical AfL research has been largely on teachers' knowledge, skills, and practices. This research has pointed to instances in which the fidelity of AfL adoption in classrooms has ranged widely, suggesting an overall patchy implementation despite the dominance of AfL discourse across educational systems. Further, even in high fidelity instances, students may not experience AfL practices as teachers intend (Cowie, 2009); hence, it is important to understand students' perspectives towards this pedagogical approach given it increasing presence across educational policies and contexts (Klenowski, 2009).

Studies that have included students typically do so by using achievement data, or proxy indicators, as metrics to demonstrate the impact of AfL on student learning (e.g., Brown, 2011; Brown \& Hirschfeld, 2007, 2008). Numerous studies have provided supporting evidence for AfL implementation, many citing medium to large effect sizes favouring increased achievement (e.g., 
Glasson, 2008; Love, 2009; Stiggins, 1999, 2006). A small number of studies have examined students' general conceptions of assessment (e.g., Brown, 2011; Brown, Iriving, Peterson, \& Hirschfeld, 2009) with a subset beginning to document students' responses to specific AfL strategies (e.g., Cowie, 2009; Harris, Brown, \& Harnett, 2009; Remesal, 2009). Researchers have also provided counterfactual evidence towards AfL and its effectiveness, demonstrating challenges in the fidelity of AfL implementation, the measurement of its impact, and the determination of differential gains in student achievement (e.g., Bennett, 2011; Shute, 2008). Further, foundational claims rendered through Black and Wiliam's (1998) seminal research have been repeatedly critiqued primarily based on their data sources and methodology for arriving at conclusive evidence (Bennett, 2011; Dunn \& Mulvenon, 2009). As Bennett (2011, p. 14) deduced from his critical review of formative assessment literature, "the research does not appear to be as unequivocally supportive of formative assessment practice as it is sometimes made to sound." That said, while researchers may have yet to establish conclusive evidence on the impact of AfL, it is difficult to argue with the fundamental logic that formative assessment information and feedback-driven teaching has the potential to improve instruction and enhance student learning.

We understand AfL to be the use of "everyday practices" (Klenowski, 2009, p. 264) by teachers and students "to decide where the leaners are in their learning, where they need to go and how best to get there" (Broadfoot et al., 2002, p. 2). Specifically, AfL involves teachers and students collaboratively establishing learning targets and success criteria and then actively using assessments (of various forms) to provide self-, peer-, and teacher-feedback on student learning toward the established targets (Stiggins, 2002). The implementation of AfL in classrooms ranges on a continuum from no implementation to deep integration (e.g., Boyle \& Charles, 2013; 
Marshall \& Drummond, 2006; Suurtamm, Koch, \& Arden, 2010). Marshall and Drummond (2006) distinguished AfL implementation as either enacting the spirit of AfL or the letter of AfL, the former involving pervasive implementation across teaching and learning within a classroom culture and the latter involving procedural and incremental implementation of AfL strategies. As observed in Marshall and Drummond's study, teachers who incorporated the spirit of AfL were more likely to promote student autonomy and have greater internal efficacy. Despite its potential benefits to teaching effectiveness and student learning, researchers have identified several challenges to effective AfL implementation and have encouraged continued in-service professional learning opportunities that move teachers from implementing the letter to the spirit of AfL in classrooms (e.g., DeLuca, Luu, Youyi, \& Klinger, 2012; Heritage, Kim, Vendlinski, \& Herman, 2009). One central area for investigation remains students' responses to varying levels of AfL implementation.

Our intention in this paper is to provide data from students' perspectives on the use and value of a AfL pedagogical approach within their learning from a large student population. Data for this study were collected from over 1000 elementary students from across an Ontario school district to explore how students' perspectives on AfL approaches differed based on their grade level. In particular, this study addressed the following research questions:

1. What AfL approaches do students report using in their classroom?

2. How frequently do students report using various AfL approaches in their classroom?

3. What AfL approaches do students perceive as valuable for their learning?

4. How do students' use and value of AfL approaches differ by grade level?

\section{Research on Students' Responses to AfL}


Studies have explored students' responses to assessment practices generally and on those designed specifically for formative functions (e.g., Brown et al., 2009; Cowie, 2009; Harris, Brown, \& Harnett, 2014; Remesal, 2009). McInerney, Brown, and Liem's (2009) edited volume contained several empirical studies on students' perspectives to classroom assessment from primary to higher education contexts. Several of these studies explored students' general perspectives to a variety of assessment orientations using a version of the Students' Conception of Assessment (SCoA) inventory (e.g., Brown, 2011; Brown et al., 2009). While these studies are informative, they do not focus discretely on formative functions of assessment, rather they consider multiple purposes and practices for classroom assessment. Nonetheless, from this research, it is evident that students value a general improvement function for assessment (i.e., formative) compared with other assessment purposes.

The majority of other studies on students' responses to assessment have focused on specific AfL approaches, primarily the peer- and self-assessment processes. Explicitly exploring peer-feedback using a quasi-experimental repeated measure design, Gielen, Peeters, Dochy, Onghena, and Struyven (2010) found justified peer-feedback was more important than accurate negative peer-feedback for secondary students ( $N=43$, Grade 7$)$ in Belgium. Similarly, Rakoczy, Harks, Klieme, Blum, and Hochweber (2013) found secondary students ( $N=146$, Grade 9 ) in Germany reported process-oriented feedback (i.e., general statement, strengths, weaknesses, examples, and suggestions for improvement or strategies) as more useful than social-comparative (i.e., grade) feedback. Hence, feedback is valued differently by students based on the type of feedback provided and its perceived evidentiary basis (i.e., justifiable feedback).

Additional studies have explored students' responses to assessment in AfL-rich learning contexts using qualitative methods (e.g., Cowie, 2009; Harris et al., 2009; Remesal, 2009). 
Harris et al. (2009) conducted focus groups in New Zealand with 46 primary and secondary students (Grades 5-9), in which students drew a picture of assessment and discussed it afterwards. While it was known that AfL practices were commonly implemented across these students' classrooms, only a few primary and secondary students drew an AfL task (e.g., one student drew a type of peer/self-assessment) but most students drew students taking tests. Harris et al. found students typically viewed assessment as an individual activity, and that the higher the grade level, the more likely a student had a limited and negative view of assessment. As a result, the authors concluded, "students may view these practices simply as part of teaching and learning and not as 'assessment' per se" (p. 77). The authors also note that many students did not value peer- or self-assessments, and preferred teacher-feedback, because students were concerned with the reliability and validity of peer-feedback and were insecure about sharing their work with peers.

Harris et al.’s (2009) findings were largely paralleled in a focus group study of 41 secondary students (Grades 8-9) in New Zealand (Peterson \& Irving, 2008). Students in this study valued teacher-feedback over peer- or self-assessments, noting that assessments were irrelevant if they were student directed. Specifically, students in this study wanted to "know what and how to improve" (p. 242) and wanted feedback that also contained an initial grade so that they knew their progress towards their summative grade. Even studies that have found students value peer-assessment (e.g., Gamlem \& Smith, 2013; Tsivitanidou, Zacharia, \& Hovardas, 2011) identified similar concerns regarding feedback reliability and validity as well as the quality of feedback to direct learning. Specifically, Tsivitanidou et al.'s (2011) study involved interviewing 10 secondary students (Grade 7) in Cyprus and found students valued peerassessment opportunities, which were implemented as unsupported, reciprocal, online, and 
anonymous feedback. However, these participants were concerned that students did not use the same criteria across peer assessors and that peer feedback was inconsistent with expert/teacher feedback. In Norway, Gamlem and Smith (2013)'s study population of 11 secondary students (Grades 8-10) also identified challenges related to the subjectivity of peer-assessors and the lack of using success criteria to provide feedback.

In 2009, Cowie purposefully examined the value of informal and formal formative assessment practices using two New Zealand data sets, including data from 22 primary and secondary classrooms. In contrast to the above studies, she found primary and secondary school students valued "informal interactions with teachers, and peers" (p. 85) to provide feedback on their learning. Specifically, students valued talking with teachers, receiving feedback, and asking questions in one-on-one or small group settings. Students valued peer-feedback when it was presented using accessible student-friendly language; however, when peer feedback was not in alignment with their own beliefs about their work students typically sought teacher feedback.

In a later study conducted in New Zealand, Harris et al. (2014) administered a questionnaire that included the Student Conceptions of Feedback (SCoF-III) inventory and a list of 15 feedback practices to 193 primary and secondary students (Grades 4-9). Students were also asked to draw a picture of a feedback experience. The authors found significant differences between primary and secondary students: primary students had a greater AfL conception towards feedback, whereas secondary students reported using teacher-feedback for evaluative purposes more often. Using a similar methodology, Remesal (2009) conducted two case studies with second grade classrooms in Spain. Through semi-structured interviews with six students, in which they were asked to discuss and write about or draw an assessment task, she found that 
students were more active in their learning when teachers used AfL-oriented practices and were more passive when teachers used more evaluative assessment practices.

Overall existing studies of students' responses to AfL suggest students' reactions differ depending upon teacher intention and actions, students' general perceptions of assessment, and the classroom culture towards assessment. As suggested by Remesal (2009), it is likely that the more explicit and structured teachers are about their classroom assessment practices, the "more accurately [students will] perceive particular assessment intentions” (p. 49). While existing research has begun to explore $\mathrm{K}-12$ students' responses to assessment, many of the studies are situated in New Zealand and Europe, and many only include students' reactions towards a subset of AfL approaches (e.g., peer-assessment). Few studies have leveraged a large sample size to focus discretely on student's responses to an AfL pedagogical approach as implemented differentially based on teacher education and grade level. Further, few studies provide data from a North American context.

\section{Method}

\section{Context}

Data for this study were derived from students in one public school district in South Eastern Ontario. The school district includes approximately 70 elementary schools and nearly 20 secondary schools serving urban, suburban, and rural communities. The majority of students in the district are from English speaking backgrounds, with approximately $20 \%$ of students in the district on Individual Education Plans. This school district had an established commitment to the implementation of AfL through a dedicated professional learning program. The professional learning program worked to build teacher capacity in AfL through various methods including (a) teacher coaching by a district assessment consultant, (b) large-group PD workshop sessions, and 
(c) instructional rounds with peer teachers implementing AfL (see DeLuca, Klinger, Pyper, Shulha, \& Woods, 2015, for further description on the professional learning program). This professional learning program established foundational learning for teachers in the area of AfL and supported them in the implementation of AfL principles in their classrooms. As a result, teachers were implementing far more than the 'letter' of AfL - a procedural adoption of pre-set AfL strategies - and instead worked continuously to revisit AfL as a pedagogical approach that pervaded their teaching practice (i.e., moving toward the 'spirit' of AfL). To this end, both teacher coaching by the assessment consultant and the instructional rounds process enabled teachers to continually deepen their integration of AfL within their teaching through sustained professional learning and reflective inquiry. Across the school district, 15 teachers had participated in this professional learning program for two academic years and 15 teachers for one academic year. The remaining teachers in the school district were not directly involved in the professional learning program. Students in classrooms of teachers participating in the AfL professional learning program provided data for this study.

\section{Data Collection}

Data were collected through: (a) student surveys with all students (K-12; ages 4-18) of teachers participating in the AfL professional learning program, and (b) portfolio-based interviews with 12 purposefully selected students from six participating teachers' classrooms.

\section{Student Survey}

A survey was used to determine K-12 students' use of AfL approaches in classroom learning and students' perspectives on the value of various AfL approaches in their learning. The survey was developed in collaboration with the school district assessment consultant and reviewed by a panel of 10 elementary and secondary teachers to ensure its accessibility and 
readability for students in grades K-12. Based on panel feedback, the scale for the items was reduced from a five-point Likert scale to a three-point Likert scale. While this decision limited data analyses, the panel of teachers argued that many students would have difficulties (especially in the early primary level) responding using a five-point scale.

The final survey presented students with three sections and 34 items, each having multiple items, plus 3 demographics questions. The survey was presented in two formats (a) a paper based format for Grades K-3 students, and (b) an electronic format for Grades 4-12. The survey was administered to all students of teachers involved in the school board's AfL professional learning program through in-person researcher visits to Grade K-12 classrooms. For students in Grades $\mathrm{K}-3$, researchers orally administered the survey to students face-to-face to provide clarification on questions.

In total, we received 1231 partially to fully complete student surveys. Prior to data analyses, student surveys were removed if students had a high proportion of missing data (more than 10\%), incompatible demographic data (e.g., age 19 in Grade 2), and overly rapid completion of the online survey (i.e., less than 2 minutes to complete). In total, 152 surveys were not included in the analyses, resulting in a final sample of 1079 surveys for analyses. An analysis of the removed surveys indicates that there was no systematic bias in those surveys that were removed (i.e., the removed surveys were distributed across grades and groups).

Student responses were grouped by grade level, then data were analyzed with respect to four grade divisions: Primary (Grades K-3; ages 4-9), Junior (Grades 4-6; ages 9-12), Intermediate (Grades 7-8; ages 12-14), and Senior (Grades 9-12; ages 14-18). Of the completed surveys, approximately two thirds of the students were in Primary and Junior grades, with the 
remaining in Intermediate and Senior grades. Table 1 presents participants' demographic information.

INSERT TABLE 1

\section{Student Interviews}

Data were also collected through interviews with 12 purposefully selected students. The school board assessment consultant selected six teachers from those who had been participating in the AfL professional learning for both years. Selected teachers were those that had a strong commitment to implementing AfL approaches throughout their teaching. These teachers then identified two students in their classes that were performing at different achievement levels (i.e., generally performing above provincial expectations and performing below provincial expectations), for a total of 12 students across six classrooms.

For each of the 12 students, teachers facilitated the student's construction of an assessment portfolio that provided sample assessments (formative and summative) from these students in the areas of mathematics and language arts. The portfolio maintained at least six assessments that demonstrated AfL activities and student responses to these activities. For example, a student might have selected a self-assessment he/she found beneficial, or the student might have selected a summative task that included descriptive feedback on his/her learning. Work samples were selected from over an eight-month period during the school year. Once students and teachers had selected their assessment samples, 30-minute interviews were conducted with each student individually by the school board assessment consultant (not the classroom teacher). The assessment consultant was trained on the interview protocol by the research team and the interviews were video-recorded to ensure the protocol was followed. The 
semi-structured questions focused on students' experiences with various AfL approaches (e.g., learning goals, success criteria, feedback) and aspects of the AfL process students found valuable to their learning. Specifically, students were asked to: (a) describe their assessment samples, (b) identify the learning goals and success criteria in relation to the assessment tasks, (c) describe any feedback processes that facilitated their learning, and (d) comment on additional supports that would benefit their learning.

\section{Data Analysis}

Survey data were analyzed through descriptive and inferential statistics, and factor analysis using SPSS. Descriptive statistics were used to provide contextual information on participants and general response trends. Factor analyses procedures, using principal axis factoring with direct quartimin rotation, were used to group one section of survey items into subscales. Factor analyses procedures were not conducted on other two survey sections because we were interested in the group level responses for each AfL approaches. Due to violations against assumptions of homogeneity of variance and normality, non-parametric inferential statistics (Kruskal-Wallis and Mann-Whitney U tests) were used to determine if systematic differences with respect to the survey items and subscales could be identified across groups.

Interview data were analyzed using a standard thematic coding process (Namey, Guest, Thairu, \& Johnson, 2008; Patton, 2002). From an initial analysis of data, a code list was generated and then codes were grouped into broader thematic categories. Codes with a high degree of co-occurrence (i.e., two or more codes used for same data) or codes that had a logical association were clustered into themes (e.g., purposes of feedback and sources of feedback were clustered into descriptive feedback). Two themes were identified from the qualitative data. Direct participant quotations were used to explain and highlight themes. Three researchers 
reviewed and analyzed all data to ensure high rater-reliability ( $>90 \%$ inter-rater agreement). In cases where raters did not initially agree on coding, data were discussed until consensus was reached.

\section{Results}

Results from the student survey and interviews are presented separately. First, survey results are described for the overall student sample as well as by grade divisions (i.e., Primary, Junior, Intermediate, Senior). Survey results are presented in relation to: (a) students' perspectives on the use and frequency of AfL approaches in their classroom, and (b) students' perspectives on the value of AfL approaches to support their learning. Second, themes from interviews with the 12 students are described and, as appropriate, compared to survey results.

\section{Survey Results}

\section{Use and Frequency of AfL Approaches}

In Section 1 of the survey, students were asked to report the frequency with which they used 16 common AfL approaches in their classrooms using a three-point scale $(1=$ never; $2=$ sometimes; $3=$ always). The 16 items in this section loaded onto three subscales that were subsequently named: Shared Success Criteria and Learning Goals, Collaborative Work with Peers, and Student Involvement with Feedback. The scree plot, parallel analysis, and interpretability all suggested three subscales. These three subscales had acceptable or good internal consistencies of .84, .67, and .78, respectively. One item in Section 2, We work independently when we are learning, was not strongly associated with any subscale, thus students' responses to this item were not analyzed further. Table 2 summarizes descriptive statistics and factor loadings for the 16 items in Section 1. 
Table 3 presents descriptive statistics for students' use of AfL approaches for the full student sample and by grade division. Overall, students reported they most frequently used Shared Success Criteria and Learning Goals $(M=2.41, S D=.39)$ and least frequently used Student Involvement with Feedback $(M=1.96, S D=.52)$. Primary students $(M=2.34, S D=.38)$ reported the lowest frequency of use of Shared Success Criteria and Learning Goals $(p<.05)$. No significant differences were found with respect to Collaborative Work with peers across grade divisions. Senior students $(M=1.79, S D=.58)$ reported the lowest levels of Student Involvement with Feedback compared to students in other grades $(p<.05)$; however, Intermediate students reported $(M=2.01 ; S D=.49)$ higher levels of Student Involvement with Feedback compared to Primary students $(M=1.92 ; S D=.54 ; p<.05)$.

\section{INSERT TABLE 3}

\section{Value of AfL Approaches}

Survey Section 2 asked students about their perceived value of six AfL approaches during a time when they were confused about their next steps in learning using a three-point scale $(1=$ no; $2=$ a bit; $3=y e s)$. Table 4 presents the descriptive statistics for Section 2. Overall, students valued teacher feedback most to clarify their next steps in challenging learning situations $(M=2.53, S D=.65)$, followed by their appreciation of clear of success criteria $(M=2.48$, $S D=.64)$. Interestingly while most students reported that success criteria were helpful at points of confusion in learning, Senior students valued clear success criteria less than students in other divisions $(p<.05)$. Most students reported that they use teacher or peer feedback to inform next steps $(M=2.43, S D=.68)$, however students across divisions agreed that peer feedback was least helpful in clarifying next steps. Notably, Intermediate students were more positive about peer 
feedback compared to Primary, Junior, or Senior students, although these differences were not statistically significant.

INSERT TABLE 4

Section 3 asked students to rate the helpfulness (i.e., value) of nine AfL approaches to their overall learning ( $1=$ not helpful; $2=$ somewhat helpful; $3=$ very helpful; na=not applicable). Table 5 summarizes the means on the helpfulness of AfL approaches by students' grade divisions. Across all students and grade divisions, teacher feedback was considered the most helpful approach. Success criteria was the second most helpful approach across students, however Senior students reported that success criteria were significantly less helpful than the other divisions $(p<.05)$. Giving feedback to peers was the least helpful AfL approach reported by students overall and in each division, however Primary students reported that giving feedback to peers was significantly more helpful than the other grade divisions $(p<.05)$. With respect to students' grade divisions, students did not significantly vary on the reported helpfulness of setting personal goals, working in groups, working independently, and teacher-feedback. Senior students were more likely to report lower levels on the helpfulness of learning goals, success criteria, giving feedback to other students, and using success criteria to support their learning compared to students in other grades $(p<.05)$, indicating that Senior students found AfL approaches less helpful overall.

INSERT TABLE 5

\section{Interview Results}


The 12 portfolio-based interviews with students across grade divisions (Primary through Senior) confirmed survey results related to students' use and value of AfL approaches in their learning. In addition, two main themes emerged that further described students use and valuing of: (a) learning goals and success criteria, and (b) descriptive feedback. We argue that the dominant presence of these two themes reflect students' general conceptions of AfL across teaching divisions: students understand AfL as the use of learning goals, success criteria, and feedback to support their learning. Within each of these themes, students described key AfL approaches and processes to enhance their effectiveness in promoting learning.

\section{Learning Goals and Success Criteria}

Students across divisions spoke about the value of learning goals and success criteria to support their learning throughout the school year. Within this theme, three codes were identified: (a) developing learning goals and success criteria, (b) helpfulness of learning goals and success criteria, and (c) uses of learning goals and success criteria.

Developing learning goals and success criteria. Students reported that their teachers were heavily involved in determining learning goals and success criteria. According to one student, "My teacher tells us the goals and criteria at the beginning of class. Then we know what we are learning about." In some cases, students could choose which learning goals and success criteria to focus on at a given time, based on their previous work and with teacher guidance. Some students described the process of developing success criteria through class discussion, with teachers central to facilitating this process.

Helpfulness of learning goals and success criteria. During the interviews, students pointed out examples of learning goals and success criteria displayed on their classroom walls, explaining that they referenced these regularly to monitor their progress during individual and 
group work periods. In addition, students shared artifacts related to learning goals and success criteria (e.g., written on worksheets, checklists, and sticky notes within their assessment portfolios). All students, regardless of achievement level or grade division, agreed that learning goals helped to guide their current and future learning efforts. As one Primary/Junior student stated, "Learning goals encourage me to do better and try harder."

Sample success criteria differed by grade and subject. For example, success criteria in Primary/Junior writing included: make work readable, add details, use finger spaces, add capitals after periods, and end with a bang. Intermediate/Senior writing success criteria included using: proper punctuation, appropriate grammar, a variety of sentence, and rich vocabulary. In both cases, the success criteria were articulated in student-friendly language, appropriate to each student's grade. Students described the process of referencing these success criteria regularly throughout work periods to ensure they were on track toward learning goals. As one Primary/Junior student elaborated, "I go over and look at the criteria to help me remember things. I can go back to my desk and make sure I'm doing everything I need to.” An Intermediate/Senior student talked about his class' ongoing efforts to more independently develop success criteria with decreased teacher guidance, suggesting a move toward greater student autonomy in AfL processes related to learning goals and success criteria.

\section{Descriptive Feedback}

Student interviews complemented survey results by providing a deeper understanding of students' responses to and use of feedback in the learning the learning process. Within this theme, two codes were identified: (a) purposes of feedback, and (b) sources of feedback. Students across grade divisions conveyed the importance of receiving multiple sources of descriptive feedback in relation to success criteria to guide their learning. 
Purposes of feedback. In general, students classified feedback as 'positive' (i.e., things done well or correctly) or 'negative' (i.e., things to improve upon). Most students identified that feedback helped them improve their work in a variety of subjects including writing, math, and reading. One students summarized, "Feedback helps because it tells us what we need to do better next time." A few students noted that they receive different amounts of feedback in different subjects, depending on their current levels of achievement in each subject area. For example, a student working at Level 3 in math and Level 2 in writing shared, “I don't get a lot of feedback in math, but I get more in English because my writing isn't as great as my math. In writing I need to work on my spelling, grammar, sentence structure, and adding details."

While students appreciated the formative nature of feedback they classified as negative, students who were approaching provincial standard (i.e., working at Level 2) tended to prefer positive over negative feedback. As one student working at Level 2 articulated, "Good feedback is more helpful and means you have less to work on. Bad feedback is when people say there are a lot of problems with your work - they're saying bad things about something you worked hard on." With regards to negative feedback, some students at Level 2 "forget to use feedback" or felt that "feedback is too hard to use", so they did not incorporate it into future work. However, students who were at provincial level (i.e., Level 3) or between Levels 2 and 3 tended to view negative feedback as more constructive, stating that positive feedback “doesn't really tell you what to do.” A Primary/Junior student working between Levels 2 was encouraged with the following feedback, "You need to keep doing it until you get all positive feedback. It gets easier over time. It's fun!” An Intermediate/Senior student working between Levels 2 and 3 added, "Feedback is useful because you know what your mistakes are and what you did well in and what you can do to improve things." 
Sources of feedback. Students also spoke about benefits and challenges associated with descriptive feedback from various sources, including teachers, peers, and through selfassessment. Their perspectives regarding feedback sources were consistent regardless of their level of achievement (i.e., Level 2, 2 to 3, or 3). Overall, students viewed teacher feedback as the most useful and credible source. They identified several challenges associated with peer feedback and spoke about self-assessment as an opportunity to enhance their work and reflect on successes. The following sections elaborate student experiences with these three feedback sources in more detail.

Teacher feedback. Students regularly received teacher feedback throughout learning periods and valued it as most helpful in relation to other feedback sources. Consistent with survey results, students valued teacher feedback most to support their learning. In Primary/Junior grades, the teacher was considered the primary source of feedback. As one student explained, "My teacher decides what feedback to give me by looking at my work and deciding how it looks by looking at some of the criteria. She gives feedback on the criteria I don't have." Intermediate/Senior students noted that teacher feedback "provides a different point of view in relation to my own self-assessments" and "helps me make sense of things I don't understand." One Intermediate/Senior student discussed a time when she disagreed with her teacher's feedback, but they worked together to incorporate it and improve her work. In general, students viewed teacher feedback as most credible and, in cases of conflicting feedback messages, prioritized this source over peer feedback or self-assessment.

Peer feedback. As in survey results, students less consistently leveraged peer feedback from classmates and gave this source of feedback mixed reviews. Typically, students used success criteria to determine the feedback to give their peers. In some cases, the peer feedback 
received by students was considered too broad (e.g., "you need to work more on writing"), limited (e.g., "my classmates just point out grammar issues"), or merely a repetition of teacher feedback, (e.g., "my teacher already told me that"). While students appreciated peer feedback because it provided an alternative point of view to teacher feedback, they did not always agree with or incorporate feedback from peers. Students stressed the importance of peer feedback being 'true'; one student explaining that "feedback [from peers] has to be true so I know what to do better next time.” One Primary/Junior student shared, “I don't always use the [peer] feedback I get because sometimes it isn't true. I'm not sure why [peers] give feedback that isn't true. I guess sometimes they make mistakes." An Intermediate/Senior student noted, "Sometimes I disagree with the peer feedback I get. For example, one time my classmate said it's great, but my teacher said to add more detail." In cases where teacher and peer feedback conflicted, students deferred to teacher feedback over feedback from peers. Alternatively, when feedback from multiple peers engaged in group work differed, students discussed the importance of navigating conflicting points of view: "If one of us thinks it's right and one of us thinks it's wrong, we have to work it out and agree. Sometimes you can have a 'good fight' to get to an agreement and figure it out together."

Despite challenges associated with peer feedback, students also shared positive experiences. First, students considered success criteria to determine what feedback to give their peers. According to one Primary/Junior student, following this process "helps me understand how other people feel about giving feedback." Second, a few Primary/Junior students talked about receiving important teacher guidance on how to provide feedback to their classmates in relation to success criteria. As one Primary/Junior student described, "My teacher tells me what they might be working on and what they might need to work on. That helps me know what 
feedback to give.” Finally, an Intermediate/Senior student used the peer feedback process to enhance his own work, explaining, "I compare [my peer's] work to my own to decide ow to give feedback — what they did well and what they didn't do. If a peer has done something really well, it also gives me something to aim for myself.” In these ways, the peer feedback process offered valuable learning opportunities for the students providing it.

Self-assessment. A majority of students described the regular use of self-assessment to support their learning toward goals. A few Primary students did not recognize the term 'selfassessment', however they readily described the use of processes associated with selfassessment. Typically, students engaged in the process of self-assessment by comparing their current work to success criteria throughout learning periods (beginning, middle, and end), guiding their progress toward learning goals. Specifically, students referenced learning goals and success criteria displayed on classroom walls or in checklists embedded in or attached to their work samples. As one Primary/Junior student elaborated, "I do self-assessment by looking at the goal and criteria on the wall and writing down what I don't have. We each have our own goal that we're working on. We work on [the goal] until we get good at it, then we move to a different goal." An Intermediate/Senior student stated, "When we start learning about something, we write what we already know. At the end, we write what we know now."

Some Primary/Junior students talked about engaging in self-assessment of work samples by giving themselves self-assessment on sticky notes (e.g., 'stars and wishes' or giving themselves no, half, or full checkmarks on checklists based on success criteria). As with peer feedback, students emphasized the importance of "being honest" in self-assessment. For example, one student explained, “I know I need to be honest [with self-assessment]. If I'm not trying to be honest, then I would probably give myself checkmarks for everything." Among all 
students, there was a consensus that self-assessment processes provided valued opportunities to reflect on progress and celebrate successes in relation to learning goals. Moreover, selfassessment using success criteria seemed to provide critical scaffolding that enabled students' learning processes and enhanced their independence and self-monitoring during individual and group work.

\section{Discussion}

Despite the rapidly growing AfL movement evident in policy and practitioner literature over the past decade (Birenbaum et al., 2015; Klenowski, 2009; Swaffield, 2011), there has been comparatively limited research on students' responses to AfL. The majority of existing research has either focused on students' general responses to various assessment conceptions or on specific AfL approaches (e.g., peer-feedback) largely from New Zealand and European contexts (e.g., Brown et al., 2009; Cowie, 2009; Gamlem \& Smith, 2013; Harris et al., 2009). In this paper, we provided a Canadian perspective from over $1000 \mathrm{~K}-12$ (ages 4-18) students on their reported use, frequency, and value of various AfL approaches through multiple data collection methods - surveys and portfolio-based interviews.

It is evident that students use and value AfL approaches differently based on their grade level (i.e., Primary, K-3; Junior, 4-6; Intermediate, 7-8; Senior, 9-12). In particular, survey results indicated that Junior students were most positive overall about the use and value of AfL approaches to support learning, while Primary and Senior students were less positive. Specifically, survey results indicated that Primary students were less likely to use learning goals and success criteria to guide their learning. However, interviews with Primary students revealed that these early learners could re-state specific learning goals and success criteria in detail even 
though they did not use the language associated with AfL in their articulations. This suggests that Primary students may lack the language of AfL but use and value AfL approaches.

Senior students reported that their teachers regularly used AfL approaches in class, however they were less likely to use these approaches when confronted with challenging learning situations. Instead, Senior students rely on traditional support structures (i.e., directly seek feedback from their teachers) when faced with learning challenges. This preference for direct teacher support may reflect the perception of teachers as 'experts' and the continued valuing of teacher feedback in contexts where grades have greater consequences for postsecondary opportunities (Harris et al., 2014). Additional research that targets Senior students' perceptions of peer- and self-assessment in comparison to teacher-feedback is warranted to better understand how these students value AfL in relation to graded tasks.

In addition to exploring students' use of AfL approaches, we also identified AfL approaches that students find most helpful in their learning. In general, students reported that success criteria and teacher feedback were most helpful in their learning. Further, in alignment with studies from New Zealand (e.g., Harris et al., 2009; Peterson \& Irving, 2008), students surveyed in this sample generally did not value peer-assessments. However, interviews elucidated nuanced student responses to peer feedback and highlighted the perceived benefits of both giving and receiving peer feedback to support learning. Among students interviewed, it was clear that success criteria helped facilitate peer feedback processes and reduced previously identified issues with peer feedback (e.g., lack of credibility, lack of detail, redundancy).

Our results suggest that using AfL approaches is a learned behaviour; students need to be explicitly taught about AfL concepts, terminology, and use over time. In our study, Senior students were able to identify when their teachers were using AfL approaches; however, we 
would argue that given the fairly recent inclusion of AfL concepts and terminology in the public education system, even the Senior level students in this study have yet to fully internalized AfL approaches as a habit for their learning. Furthermore, in accordance with previous research (Harris et al., 2009; Peterson \& Irving, 2009), students in our study resorted back to traditional support structures in challenging learning contexts. Future research that tracks students with prolonged and early exposure to AfL approaches will be valuable to empirically determine whether or not AfL can shift students' learning habits towards more self-regulating approaches over time.

This study also highlights that, despite a board-wide professional learning program to engage K-12 teachers and students in AfL processes, students still perceived teachers as the driving force in classroom learning. Aligned with previous studies (Klinger, Volante, \& DeLuca, 2012; Marshall \& Drummond, 2006), students across divisions indicated that teachers were primarily responsible for identifying learning goals and guiding students in the development of success criteria. Moreover, teacher feedback was consistently preferred over peer feedback or self-assessment. In these ways, students still relied heavily on teachers to guide and support learning. We suggest that the two-year professional learning program supported the 'letter of AfL' in classrooms of engaged teachers (i.e., procedural use of AfL practices), but had not yet cultivated the 'spirit of AfL' in involved classrooms or beyond (i.e., pervasive implementation across teaching and learning within a feedback-driven classroom culture) (Marshall \& Drummond, 2006). Establishing a culture of AfL within classrooms and schools requires (a) sustained commitment to using AfL approaches across subjects and grade levels, and (b) significant time to allow teachers to fully integrate AfL into their pedagogical approaches. 
While findings from this study provide important information on students' differential responses to AfL approaches based on grade divisions, they must be interpreted with awareness of the study's limitations. We recognize limitations to this study related to sample population and data collection methods. Data from this study are reflective of students in one school district in South Eastern Ontario, and student interviews were limited to 12 students from six purposefully selected classrooms. Future research should extend data collection to include students from other jurisdictions, as school systems differ in their orientation and support of AfL approaches throughout regions. In addition, interviews with a greater number of students will be important to develop a broader understanding of how students use and value AfL in their learning. Second, we used the same survey instrument, written at a Primary level, for all students, regardless of age. We did this to ensure direct comparability of responses. However, we acknowledge that students may interpret and understand questions differently based on their age and explicit knowledge of AfL concepts. Further, in our effort to ensure that the instrument was easily accessible to students, we elected for a three-point scale for most items. Despite the observed and significant differences in data between groups, we recognize that a three-point scale does not fully yield discrimination of responses. Additional research should refine the instrument used in this research to reflect the developmental stages of students at various grade levels, and to ensure reliability of measure.

Data from this study presented compelling differences in students' responses to AfLbased teaching based on grade division. These differences require greater investigation. In particular, we see significant value in building on findings from this and previous research by further examining: (a) students' differential responses to various AfL approaches based on grade level, subject matter, and teacher's AfL knowledge; (b) students' use and value of AfL 
approaches in classrooms where teachers have a demonstrated and sustained commitment to AfL implementation; and (c) aspects of AfL that students often do not find as helpful in their learning (e.g., peer-assessment) in order to enhance the value of these AfL approaches. We hope that these target areas for future AfL research can serve to provoke continued and more nuanced studies into the effectiveness of AfL as a pedagogical approach to support student learning. 


\section{References}

Bennett, R. E. (2011). Formative assessment: A critical review. Assessment in Education: Principles, Policy \& Practice, 18(1), 5-25.

Birenbaum, M., DeLuca, C., Earl, L., Heritage, M., Klenowski, V., Looney, A., . . WyattSmith, C. (2015). International trends in the implementation of assessment for learning: Implications for policy and practice. Policy Futures in Education, 13(1), 117-140.

Black, P., \& Wiliam, D. (1998). Assessment and classroom learning. Assessment in Education, $5(1), 7-74$.

Boyle, B., \& Charles, M. (2013). Formative assessment for teaching and learning. Los Angeles, CA: Sage.

Broadfoot, P., Daugherty, R., Gardner, J., Harlen, W., James, M., \& Stobart, G. (2002). Assessment for learning: 10 principles. Cambridge, UK: University of Cambridge.

Brown, G. T. L. (2011). Self-regulation of assessment beliefs and attitudes: A review of the Students' Conceptions of Assessment inventory. Educational Psychology, 31(6), 731-748.

Brown, G. T. L., \& Hirschfeld, G. H. F. (2007). Students' conceptions of assessment and mathematics: Self-regulation raises achievement. Australian Journal of Educational \& Developmental Psychology, 7, 63-74.

Brown, G. T. L., \& Hirschfeld, G. H. F. (2008). Students' conceptions of assessment: Links to outcomes. Assessment in Education: Principles, Policy \& Practice, 15(1), 3-17.

Brown, G. T. L., Irving, S. E., Peterson, E. R., \& Hirschfeld, G. H. F. (2009). Use of interactiveinformal assessment practices: New Zealand secondary students' conceptions of assessment. Learning and Instruction, 19(2), 97-111.

Cowie, B. (2009). My teacher and my friends helped me learn. In D. M. McInerney, G. T. L. Brown, \& G. A. D. Liem (Eds.), Student perspectives on assessment (pp. 85-105). Charlotte, NC: Information Age.

DeLuca, C., Klinger, D., Pyper, J., Shulha, L., \& Woods, J. (2015). Building school district capacity in assessment for learning: A study on the effectiveness of an instructional rounds professional learning approach. Assessment in Education: Principles, Policy and Practice, 22(1), 122-139.

DeLuca, C., Luu, K., Youyi, S., \& Klinger, D. (2012). Assessment for learning in the classroom: Barriers to implementation and possibilities for teacher professional learning. Assessment Matters, 4, 5-29. 
Dunn, K. E., \& Mulvenon, S. W. (2009). A critical review of research on formative assessments: The limited scientific evidence of the impact of formative assessments in education. Practical Assessment \& Research and Evaluation, 14(7), 1-11.

Gamlem, S. M., \& Smith, K. (2013). Student perceptions of classroom feedback. Assessment in Education: Principles, Policy \& Practice, 20(2), 150-169.

Gielen, S., Peeters, E., Dochy, F., Onghena, P., \& Struyven, K. (2010). Improving the effectiveness of peer feedback for learning. Learning and Instruction, 20(4), 304-315. doi:10.1016/j.learninstruc.2009.08.007

Glasson, T. (2008). Improving student achievement through assessment for learning. Curriculum Leadership, 6(31).

Harris, L. R., Brown, G. T. L., \& Harnett, J. A. (2009). “Drawing” out student conceptions: Using pupils' pictures to examine their conceptions of assessment. In D. M. McInerney, G. T. L. Brown, \& G. A. D. Liem (Eds.), Student perspectives on assessment (pp. 53-83). Charlotte, NC: Information Age.

Harris, L. R., Brown, G. T. L., \& Harnett, J. A. (2014). Understanding classroom feedback practices: A study of New Zealand student experiences, perceptions, and emotional responses. Educational Assessment, Evaluation and Accountability, 26, 107-133.

Hayward, L., and Spencer, E. (2010) The complexities of change: formative assessment in Scotland. Curriculum Journal, 21(2), pp. 161-177.

Heritage, M., Kim, J., Vendlinski, T., \& Herman, J. (2009). From evidence to action: a seamless process in formative assessment. Educational Measurement: Issues and Practice, 28(3), 2431.

Ireland Department of Education and Skills. (2012). The Framework for Junior Cycle. Dublin, IRL: DES.

Klenowski, V. (2009). Assessment for Learning revisited: An Asia-Pacific perspective. Assessment in Education: Principles, Policy \& Practice, 16(3), 263-268.

Klinger, D. A., Volante, L., \& DeLuca, C. (2012). Building teacher capacity within the evolving assessment culture in Canadian Education. Policy Futures in Education, Special Issue: Developing Sustainable Assessment Cultures in School Learning Organisations, 10(4), 447460.

Love, N. (2009). Building a high-performance data culture. In N. Love (Ed.), Using data to improve learning for all: A collaborative inquiry approach (pp. 2-24). Thousand Oaks, CA: Corwin. 
Marshall, B., \& Drummond, M. J. (2006). How teachers engage with Assessment for Learning: lessons from the classroom. Research Papers in Education, 21(2), 133-149.

McInerney, D. M., Brown, G. T. L., \& Liem, G. A. D. (Eds.). (2009). Student perspectives on assessment. Charlotte, NC: Information Age.

New Zealand Ministry of Education. (2011). Ministry of Education Position Paper: Assessment (Schooling Sector). Wellington, NZ: Learning Media.

Ontario Ministry of Education. (2010). Growing success: Assessment, evaluation, and reporting in Ontario schools. Toronto, ON: Queen's Printer.

Peterson, E. R., \& Irving, S. E. (2008). Secondary school students' conceptions of assessment and feedback. Learning and Instruction, 18(3), 238-250.

Rakoczy, K., Harks, B., Klieme, E., Blum, W., \& Hochweber, J. (2013). Written feedback in mathematics: Mediated by students' perception, moderated by goal orientation. Learning and Instruction, 27, 63-73.

Remesal, A. (2009). Accessing primary pupils' conceptions of daily classroom assessment practices. In D. M. McInerney, G. T. L. Brown, \& G. A. D. Liem (Eds.), Student perspectives on assessment (pp. 25-51). Charlotte, NC: Information Age.

Shute, V. (2008). Focus on formative feedback. Review of Educational Research, 78(1), 153189.

Stiggins, R. J. (1999). Evaluating classroom assessment training in teacher education programs. Educational Measurement: Issues and Practice, 18(1), 23-7.

Stiggins, R. J. (June, 2002). Assessment crisis: The absence of assessment for learning. Phi Delta Kappan, 83(10), 758-765.

Stiggins, R. J. (2006). Balanced assessment systems: Redefining excellence in assessment. Portland, OR: Educational Testing Service.

Suurtamm, C., Koch, M. J., \& Arden, A. (2010). Teachers' assessment practices in mathematics: Classrooms in the context of reform. Assessment in Education: Principles, Policy \& Practice, 17(4), 399-417.

Swaffield, S. (2011). Getting to the heart of authentic Assessment for Learning. Assessment in Education: Principles, Policy \& Practice, 18(4), 433-449.

Tsivitanidou, O. E., Zacharia, Z. C., \& Hovardas, T. (2011). Investigating secondary school students' unmediated peer assessment skills. Leadership and Policy in Schools, 21(4), 506519. 


\section{Tables}

Table 1

Participant Demographics

\begin{tabular}{lc}
\hline & $\begin{array}{c}\text { All Students } \\
(\mathbf{n}=\mathbf{1 0 7 9 )}\end{array}$ \\
\hline Grade Division & \\
$\quad$ Primary (K-3) & 377 \\
$\quad$ Junior (4-6) & 359 \\
$\quad$ Intermediate (7-8) & 206 \\
$\quad$ Senior (9-12) & 126 \\
\hline Sex & \\
$\quad$ Male & 529 \\
$\quad$ Female & 539
\end{tabular}

Note. Of the 1079 completed surveys, only 1068 students reported their grade level. 
Table 2

Descriptive Statistics (Item Means and Standard Deviations) and Factor Loadings for Use of AfL Approaches in Class (Survey Section 1)

\section{Use of AfL Approaches in Class}

We work with our teacher to discuss the meaning of learning goals.

We work with our teacher to discuss the meaning of success criteria.

We work with our teacher to create success criteria.

We work with our teacher to create learning goals.

Our teacher checks in with us to see if we understand the success criteria.

Our teacher checks in with us to see if we understand the learning goal.

Our teacher tells us the success criteria.

Our teacher tells us the learning goals.

We set personal learning goals for ourselves.

My teacher gives me feedback on my learning.

I give feedback to other students about their learning.

Other students give me feedback on my learning.

I use the feedback I get from other students to help with my learning.

We work in pairs when we are learning.

We work in groups when we are learning.

We work independently when we are learning. *

\begin{tabular}{lccc}
\hline$\%$ of variance explained & 31.3 & 10.3 & 8.61 \\
\hline Internal consistency & .842 & .781 & .665 \\
\hline
\end{tabular}

$2.35(.63) \quad .744$

$2.30(.63)$

.733

$2.39(.63)$

.694

2.37(.64)

.692

2.36(.63)

.618

2.42(.64)

.591

2.62(.56)

.506

2.67(.51)

.500

2.14(.67)

.387

2.48(.58)

.354

$1.88(.57)$

.873

$1.85(.59)$

.770

2.11(.72)

.586

\begin{tabular}{|c|c|c|c|}
\hline $\begin{array}{c}\text { M(SD) } \\
\text { All Students } \\
\mathbf{n}=\mathbf{1 0 7 9}\end{array}$ & $\begin{array}{c}\text { Shared } \\
\text { Success } \\
\text { Criteria and } \\
\text { Learning } \\
\text { Goals }\end{array}$ & $\begin{array}{c}\text { Student } \\
\text { Involvement } \\
\text { with } \\
\text { Feedback }\end{array}$ & $\begin{array}{c}\text { Collaborative } \\
\text { Work with } \\
\text { Peers }\end{array}$ \\
\hline
\end{tabular}

Note. Factor loadings $<.30$ were suppressed. Scale: $1=$ never, $2=$ sometimes, $3=$ =always.

*Item was not strongly associated with any subscale, thus students' responses to this item were not analyzed further. 
Table 3

Means (and SD) for Use of AfL Approaches in Class Subscales (Shared Success Criteria and Learning Goals, Collaborative Work with Peers, and Student Involvement with Feedback) by Grade Division (Survey Section 1)

\begin{tabular}{|c|c|c|c|c|c|c|}
\hline $\begin{array}{c}\text { Use of AfL } \\
\text { Approaches in } \\
\text { Class }\end{array}$ & $\begin{array}{c}\text { Internal } \\
\text { Consistency } \\
(\alpha) \\
\end{array}$ & $\begin{array}{c}\text { All Students } \\
(\mathrm{n}=1079)\end{array}$ & $\begin{array}{l}\text { Primary } \\
(\mathrm{n}=377)\end{array}$ & $\begin{array}{c}\text { Junior } \\
(\mathrm{n}=359)\end{array}$ & $\begin{array}{l}\text { Intermediate } \\
\quad(\mathrm{n}=206)\end{array}$ & $\begin{array}{c}\text { Senior } \\
(n=126)\end{array}$ \\
\hline $\begin{array}{l}\text { Shared Success } \\
\text { Criteria and } \\
\text { Learning Goals }\end{array}$ & .84 & $2.41(.39)$ & $2.34(.38)^{\mathrm{A}}$ & $2.44(.37)^{\mathrm{C}}$ & $2.46(.40)^{\mathrm{C}}$ & $2.44(.45)^{\mathrm{C}}$ \\
\hline $\begin{array}{l}\text { Collaborative } \\
\text { Work with } \\
\text { Peers }\end{array}$ & .67 & $2.05(.33)$ & $2.05(.39)$ & $2.04(.24)$ & $2.03(.28)$ & $2.10(.42)$ \\
\hline $\begin{array}{l}\text { Student } \\
\text { Involvement } \\
\text { with Feedback }\end{array}$ & .78 & $1.96(.52)$ & $1.92(.54)^{\mathrm{B}}$ & $1.99(.50)^{\mathrm{C}}$ & $2.01(.49)^{\mathrm{B}}$ & $1.79(.58)^{\mathrm{A}}$ \\
\hline $\begin{array}{l}\text { Note. Collab } \\
\text { missing } 5 \text { res } \\
\mathrm{A}=\text { significa }\end{array}$ & $\begin{array}{l}\text { rative Work } \\
\text { onses. } \\
\text { t differences }\end{array}$ & $\begin{array}{l}\text { th Peers mis } \\
\text { ith } 3 \text { groups }\end{array}$ & $\begin{array}{l}\text { ing } 2 \text { respons } \\
\mathrm{B}=\text { significa }\end{array}$ & s; Student In & olvement wi & $\begin{array}{l}\text { Feedback } \\
\mathrm{C}=\end{array}$ \\
\hline
\end{tabular}


Table 4

Means (and SD) for Students' Perceived Value of AfL Approaches in a Challenging Learning Situation by Grade Division (Survey Section 2)

\begin{tabular}{|c|c|c|c|c|c|}
\hline & $\begin{array}{c}\text { All } \\
\text { Students } \\
(\mathrm{n}=1079) \\
\end{array}$ & $\begin{array}{l}\text { Primary } \\
(\mathrm{n}=377)\end{array}$ & $\begin{array}{c}\text { Junior } \\
(\mathrm{n}=359)\end{array}$ & $\begin{array}{l}\text { Intermediate } \\
\quad(\mathrm{n}=206)\end{array}$ & $\begin{array}{c}\text { Senior } \\
(\mathrm{n}=126)\end{array}$ \\
\hline $\begin{array}{l}\text { Were the learning goals clear } \\
\text { to you? }\end{array}$ & $\begin{array}{l}2.35 \\
(.62)\end{array}$ & $\begin{array}{c}2.31 \\
(.66)^{\mathrm{C}}\end{array}$ & $\begin{array}{l}2.43 \\
(.60)^{\mathrm{B}}\end{array}$ & $\begin{array}{l}2.38 \\
(.60)^{\mathrm{C}}\end{array}$ & $\begin{array}{l}2.22 \\
(.62)^{\mathrm{B}}\end{array}$ \\
\hline $\begin{array}{l}\text { Were the success criteria clear } \\
\text { to you? }\end{array}$ & $\begin{array}{l}2.48 \\
(.64)\end{array}$ & $\begin{array}{l}2.49 \\
(.65)^{\mathrm{C}}\end{array}$ & $\begin{array}{l}2.50 \\
(.61)^{\mathrm{C}}\end{array}$ & $\begin{array}{l}2.50 \\
(.64)^{C}\end{array}$ & $\begin{array}{c}2.31 \\
(.65)^{\mathrm{A}}\end{array}$ \\
\hline $\begin{array}{l}\text { Did you use the learning goals } \\
\text { and success criteria to help you } \\
\text { with your next steps? }\end{array}$ & $\begin{array}{l}2.31 \\
(.70)\end{array}$ & $\begin{array}{l}2.31 \\
(.72)^{\mathrm{C}}\end{array}$ & $\begin{array}{c}2.41 \\
(.63)^{\mathrm{B}}\end{array}$ & $\begin{array}{l}2.26 \\
(.70)^{\mathrm{C}}\end{array}$ & $\begin{array}{l}2.13 \\
(.77)^{\mathrm{B}}\end{array}$ \\
\hline $\begin{array}{l}\text { Did you receive feedback from } \\
\text { your teacher that helped you } \\
\text { with your next steps? }\end{array}$ & $\begin{array}{l}2.53 \\
(.65)\end{array}$ & $\begin{array}{l}2.45 \\
(.73)\end{array}$ & $\begin{array}{l}2.59 \\
(.60)\end{array}$ & $\begin{array}{l}2.58 \\
(.59)\end{array}$ & $\begin{array}{l}2.50 \\
(.64)\end{array}$ \\
\hline $\begin{array}{l}\text { Did you receive feedback from } \\
\text { your classmates that helped } \\
\text { you with your next steps? }\end{array}$ & $\begin{array}{l}2.06 \\
(.73)\end{array}$ & $\begin{array}{l}2.05 \\
(.78)\end{array}$ & $\begin{array}{l}2.05 \\
(.70)\end{array}$ & $\begin{array}{l}2.13 \\
(.66)\end{array}$ & $\begin{array}{l}1.98 \\
(.78)\end{array}$ \\
\hline $\begin{array}{l}\text { Did you use the feedback from } \\
\text { your teacher or classmates to } \\
\text { help you learn? }\end{array}$ & $\begin{array}{l}2.43 \\
(.68)\end{array}$ & $\begin{array}{l}2.36 \\
(.74)\end{array}$ & $\begin{array}{l}2.47 \\
(.65)\end{array}$ & $\begin{array}{l}2.50 \\
(.62)\end{array}$ & $\begin{array}{l}2.36 \\
(.69)\end{array}$ \\
\hline
\end{tabular}

Note. 54 students' responses were missing: 37 Primary, 11 Junior, 3 Intermediate, 3 Senior. $\mathrm{A}=$ significant differences with 3 groups, $\mathrm{B}=$ significant differences with 2 groups.

$\mathrm{C}=$ significant difference with 1 group at $p<.05$. 
Table 5

Means (and SD) on the Helpfulness of AfL Approaches by Grade Division (Survey Section 3)

\begin{tabular}{|c|c|c|c|c|c|}
\hline & $\begin{array}{l}\text { All Students } \\
(\mathrm{n}=1079)\end{array}$ & $\begin{array}{l}\text { Primary } \\
(\mathrm{n}=377)\end{array}$ & $\begin{array}{c}\text { Junior } \\
(\mathrm{n}=359)\end{array}$ & $\begin{array}{l}\text { Intermediate } \\
(\mathrm{n}=206)\end{array}$ & $\begin{array}{c}\text { Senior } \\
(\mathrm{n}=126)\end{array}$ \\
\hline Learning goals & $\begin{array}{l}2.31 \\
(.64)\end{array}$ & $\begin{array}{l}2.40 \\
(.61)^{\mathrm{B}}\end{array}$ & $\begin{array}{l}2.39 \\
(.59)^{\mathrm{B}}\end{array}$ & $\begin{array}{l}2.19 \\
(.66)^{\mathrm{B}}\end{array}$ & $\begin{array}{l}2.04 \\
(.71)^{\mathrm{B}}\end{array}$ \\
\hline Success criteria & $\begin{array}{l}2.41 \\
(.64)\end{array}$ & $\begin{array}{l}2.41 \\
(.64)^{\mathrm{C}}\end{array}$ & $\begin{array}{l}2.48 \\
(.60)^{\mathrm{C}}\end{array}$ & $\begin{array}{l}2.41 \\
(.67)^{\mathrm{C}}\end{array}$ & $\begin{array}{l}2.18 \\
(.70)^{\mathrm{A}}\end{array}$ \\
\hline Setting personal goals & $\begin{array}{l}2.22 \\
(.66)\end{array}$ & $\begin{array}{l}2.20 \\
(.68)\end{array}$ & $\begin{array}{l}2.25 \\
(.62)\end{array}$ & $\begin{array}{l}2.23 \\
(.68)\end{array}$ & $\begin{array}{l}2.13 \\
(.65)\end{array}$ \\
\hline Working in groups & $\begin{array}{l}2.30 \\
(.59)\end{array}$ & $\begin{array}{l}2.32 \\
(.59)\end{array}$ & $\begin{array}{l}2.26 \\
(.55)\end{array}$ & $\begin{array}{l}2.34 \\
(.62)\end{array}$ & $\begin{array}{l}2.26 \\
(.63)\end{array}$ \\
\hline Working in pairs & $\begin{array}{l}2.34 \\
(.59)\end{array}$ & $\begin{array}{l}2.29 \\
(.64)^{\mathrm{C}}\end{array}$ & $\begin{array}{l}2.32 \\
(.53)^{\mathrm{C}}\end{array}$ & $\begin{array}{l}2.47 \\
(.57)^{\mathrm{B}}\end{array}$ & $\begin{array}{l}2.35 \\
(.60)\end{array}$ \\
\hline Working independently & $\begin{array}{l}2.35 \\
(.59)\end{array}$ & $\begin{array}{l}2.33 \\
(.63)\end{array}$ & $\begin{array}{l}2.37 \\
(.56)\end{array}$ & $\begin{array}{l}2.36 \\
(.56)\end{array}$ & $\begin{array}{l}2.35 \\
(.63)\end{array}$ \\
\hline Teacher-feedback & $\begin{array}{l}2.51 \\
(.59)\end{array}$ & $\begin{array}{l}2.51 \\
(.60)\end{array}$ & $\begin{array}{l}2.51 \\
(.59)\end{array}$ & $\begin{array}{l}2.52 \\
(.58)\end{array}$ & $\begin{array}{l}2.50 \\
(.62)\end{array}$ \\
\hline $\begin{array}{l}\text { Giving feedback to other } \\
\text { students }\end{array}$ & $\begin{array}{l}2.03 \\
(.65)\end{array}$ & $\begin{array}{l}2.14 \\
(.72)^{\mathrm{A}}\end{array}$ & $\begin{array}{l}2.00 \\
(.58)^{\mathrm{C}}\end{array}$ & $\begin{array}{l}2.01 \\
(.61)^{\mathrm{C}}\end{array}$ & $\begin{array}{l}1.90 \\
(.71)^{\mathrm{C}}\end{array}$ \\
\hline $\begin{array}{l}\text { Using success criteria to } \\
\text { make sure you are on the } \\
\text { right track with your learning }\end{array}$ & $\begin{array}{l}2.34 \\
(.65)\end{array}$ & $\begin{array}{l}2.36 \\
(.67)^{\mathrm{C}}\end{array}$ & $2.41(.60)^{\mathrm{C}}$ & $\begin{array}{l}2.31 \\
(.66)^{\mathrm{C}}\end{array}$ & $2.12(.70)^{\mathrm{A}}$ \\
\hline
\end{tabular}

Note. $\mathrm{A}=$ significant differences with 3 groups, $\mathrm{B}=$ significant difference with 2 groups.

$\mathrm{C}=$ significant difference with 1 group at $p<.05$. 